\title{
APPROACH FOR DECIDING PERFECT MAINTENANCE STRATEGY FOR PRODUCTION DEPARTMENT
}

\author{
S. Phogat, Avinash Dholiwal and Nitin Shyam \\ Assistant Professor, Mechanical Engineering Department, \\ Amity University, Haryana, India
}

\begin{abstract}
ABSRACT
This paper introduces methodology focused on improving of economic efficiency of the maintenance systems by choosing the perfect maintenance strategy for production departments. In first part of the research paper basic maintenance strategies are introduced and a global overview of the methodology is presented. The second part of the paper deals with the brief characteristic of the model MAM (Maintenance Analytical Module), which was developed on the MS Excel platform as a decision support tool for maintenance managers. Description of the model is primarily focused on characteristic of its structure and benefits of its application.
\end{abstract}

Key words: Maintenance Strategy, Maintenance Management, Computerized Maintenance Management Systems, Maintenance Costs, Maintenance Analytical Module

Cite this Article: S. Phogat, Avinash Dholiwal and Nitin Shyam. Approach For Deciding Perfect Maintenance Strategy For Production Department, International Journal of Industrial Engineering Research and Development, 7(2), 2016, pp. 14-22

https://iaeme.com/Home/issue/IJIERD?Volume $=7 \&$ Issue $=2$

\section{INTRODUCTION}

Maintenance is an integral part of any production system and influences enterprise productivity. Appropriately chosen maintenance is the key element for efficient use of enterprise resources, contributes to increasing of business competitiveness and helps to produce products in required time and quality. It is therefore obvious that the choice of maintenance strategy can significantly influence the success of business.

For this reason I chose maintenance field as the target area for my doctoral thesis Strategy of maintenance system in industrial company [7], which focuses on improving of maintenance system economic effectiveness.

The main task of the thesis was to provide maintenance managers with the information necessary for selecting the appropriate maintenance strategy in the 
enterprise. To fulfill this main task I proposed and characterized steps of the methodology for selecting appropriate maintenance strategy which effectively uses allocated resources. This methodology is described in chapter 3 of this article. As a key tool integrated in the proposed methodology I designed the decision support model MAM (Maintenance Analytical Module). This model provides managers with important information for the selection of maintenance strategy.

\section{MAINTENANCE STRATEGIES}

Alsyouf [1] defines maintenance strategy as a description what events (e.g. failure, passing of time, condition) trigger what type of maintenance action (inspection, repair, or replacement). It is a set of procedures and techniques that vary from business to business. As shown in the conclusions of the work of Pinjala [3] and Alsyouf [1], the choice of maintenance strategy is strongly influenced by the business strategy of the company, production character, type of production machines used in the enterprise and by other factors. There are three main maintenance approaches (strategies) applied and combined in industrial companies.

\section{Corrective Maintenance (CM)}

This strategy can be characterized as "fix it when it breaks". It means that no maintenance procedures are carried out until a failure occurs. Advantages of this strategy are:

- small demands on inspections, diagnostics and prevention maintenance procedures that means lower direct maintenance costs

- small demands on maintenance management and planning Disadvantages of this strategy are:

- impossibility of planned and systematic approach

- failures frequently can lead to higher losses (indirect maintenance costs) than are the direct maintenance costs

\section{Preventive Maintenance (PM)}

This strategy is focused on the elimination of unplanned failures by implementing a cyclically repeating preventive inspections and preventative maintenance. Frequency is usually defined by a certain time interval or number of cycles. Advantages of this strategy are:

- reduction of the risk of unexpected failures compared to $\mathrm{CM}$

- possibility of implementation of systematic maintenance management and maintenance planning

- $\quad$ suitable for software support Disadvantages of this strategy are:

- high demands on resources: tangible, intangible (software support), human (maintenance staff)

- high direct maintenance costs (spare parts, maintenance staff wages, outsourced maintenance)

- maintenance strategy based on regular time cycles ignores actual technical conditions

Some parts are replaced although they can still be operated, on the other hand, some parts are replaced too late, which may cause deterioration in the quality of production, or need for demanding and expensive repair procedure 


\section{Condition Based Maintenance - CBM}

This maintenance strategy respects the actual technical condition identified by use of technical diagnostics methods (e.g. vibration monitoring \& analysis, infrared thermography, ultrasonic noise detection, electrical condition monitoring, etc.). Machinery and equipment are being shut down only when they have reached the limit stage of wear, or limit values of the monitored properties, which indicates the risk of failure. Advantages of this strategy are:

- outages and maintenance procedures are carried out based on actual technical condition - it means minimization of inefficiencies and losses due to early or late maintenance $=$ savings of costs of spare parts and maintenance staff wages, minimization of downtimes

Disadvantages of this strategy are:

- high costs of diagnostics equipment and software tools

- increased demands on staff in servicing diagnostics equipment and software tools

- worse possibility of maintenance planning and coordination with the production plan

Because of advantages and disadvantages of these strategies and limited resources allocated on maintenance it is usual to combine all these approaches in the companies. This claim was proofed by results of the survey among Czech industrial companies published in the article [6]. All respondents use combination of more above-mentioned maintenance strategies and they differ only in the proportion of these strategies.

However, it was discovered that there is no clearly defined methodology in the companies that would help maintenance managers to decide on which machine implement which maintenance strategy and to identify critical elements in the production processes, on which is important to focus limited maintenance resources (human and financial) in order to maximize benefits of the maintenance. Managers often have to rely on their own intuition and experience and lack sufficient information for making qualified decisions. This was the main reason for development of the methodology and for design of the MAM model described in this article.

\section{METHODOLOGY FOR SELECTING THE APPROPRIATE MAINTENANCE STRATEGY}

This part of the paper deals with a brief characterization and description of the methodology for selecting of the appropriate maintenance strategy for defined system of machines. The methodology focuses primarily on the economic benefits of implemented strategies and is primarily based on the Reliability Centered Maintenance (RCM) approach [2], [4], [5].

The main goal of the methodology is to prepare and provide information needed for the selection of the maintenance strategy for individual system elements (machines), which effectively uses resources allocated to the maintenance and has maximum benefits for the whole system. The final decision about maintenance strategy makes maintenance manager. However, he can rely not only on his experience, but also on relevant information obtained through the proposed methodology and by using the MAM decision support model.

Due to limited length of this article only global diagrams and schemes are presented. These diagrams introduces the main idea and philosophy of the 
methodology. Detailed description of individual methodology steps contain dissertation thesis [7]. Figure 1 shows the whole methodology process and overview of individual steps. In this figure is also possible to identify the field of MAM model application and links to the other information sources and software tools. Detailed information flows and links between information systems and sources within the methodology are shown on the figure 2 .

Because the methodology is very demanding on input data the possibility of its application without using advanced software tools (CMMS, SW for reliability data analysis) is very limited. It is also very important to ensure the linkages between information systems, as shown in figure 2. For integration and transformation all the maintenance data the MAM model was designed.

\section{DECISION SUPPORT MODEL MAM (MAINTENANCE ANALYTICAL MODULE)}

Model MAM was developed as an integral part of the methodology (the field of application of the model within the methodology is marked on the fig. 1 and 2). It is a decision support model (not optimization model), which represents specialized module for complex analysis of the maintenance system. Model uses big amount of input data from different information sources for generating outputs needed for decision making on maintenance strategies (see fig. 2).

The main objective of the model MAM is an information support for maintenance managers in choosing the appropriate maintenance strategy. With this main objective are connected following benefits of the model. MAM mode:

- simplifies the quantification of the direct and indirect maintenance costs;

- organizes the data about individual system elements (machines) as well as about the entire system and thus provides decision support for maintenance managers at three different levels:

- Mutual comparison of different maintenance strategies on one machine,

- Mutual comparison of system elements (machines) within the whole system,

- Mutual comparison of the strategic mixes; 


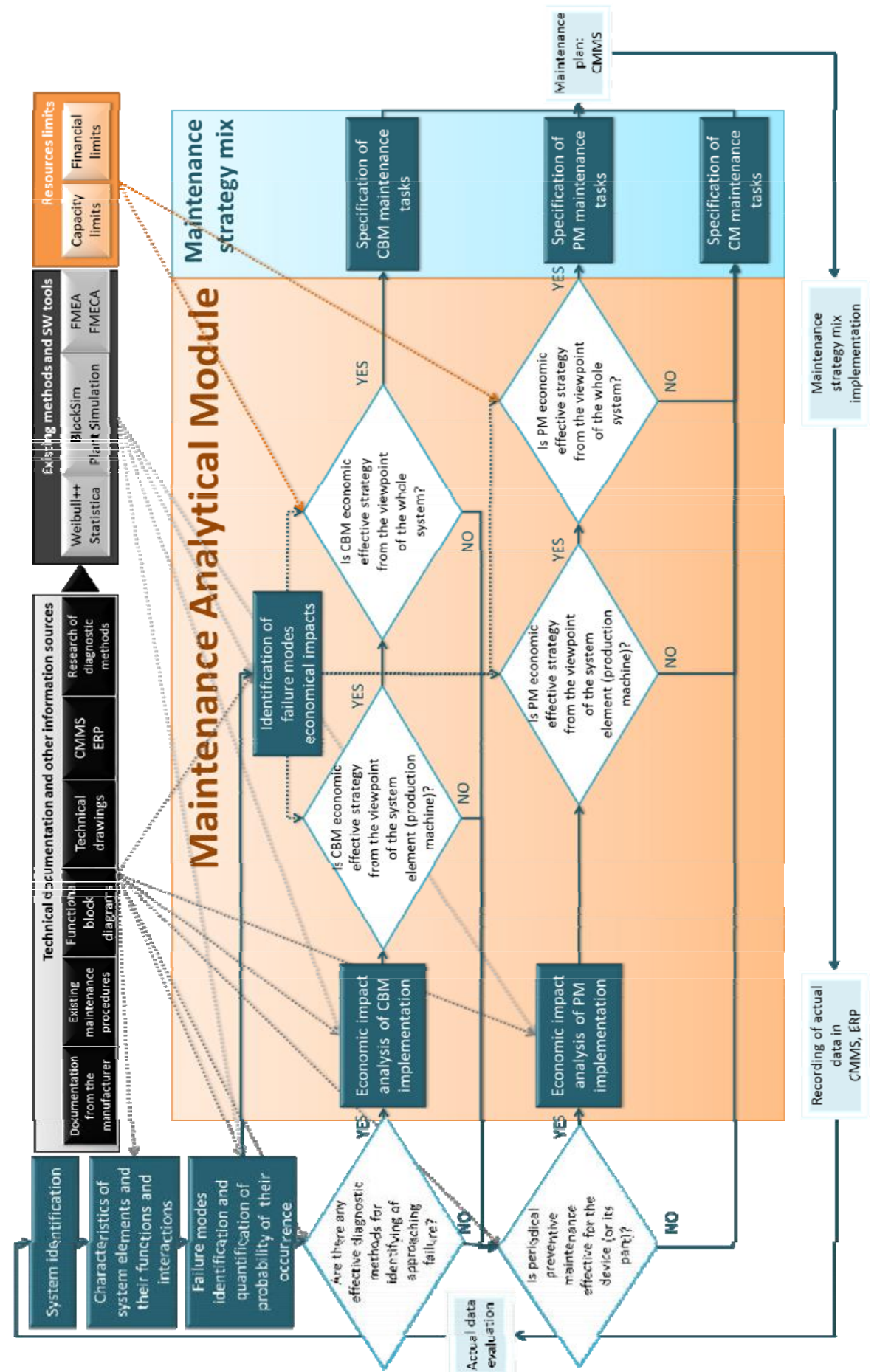

Figure 1 Process flow diagram of the methodology for deciding perfect maintenance strategy [7] 


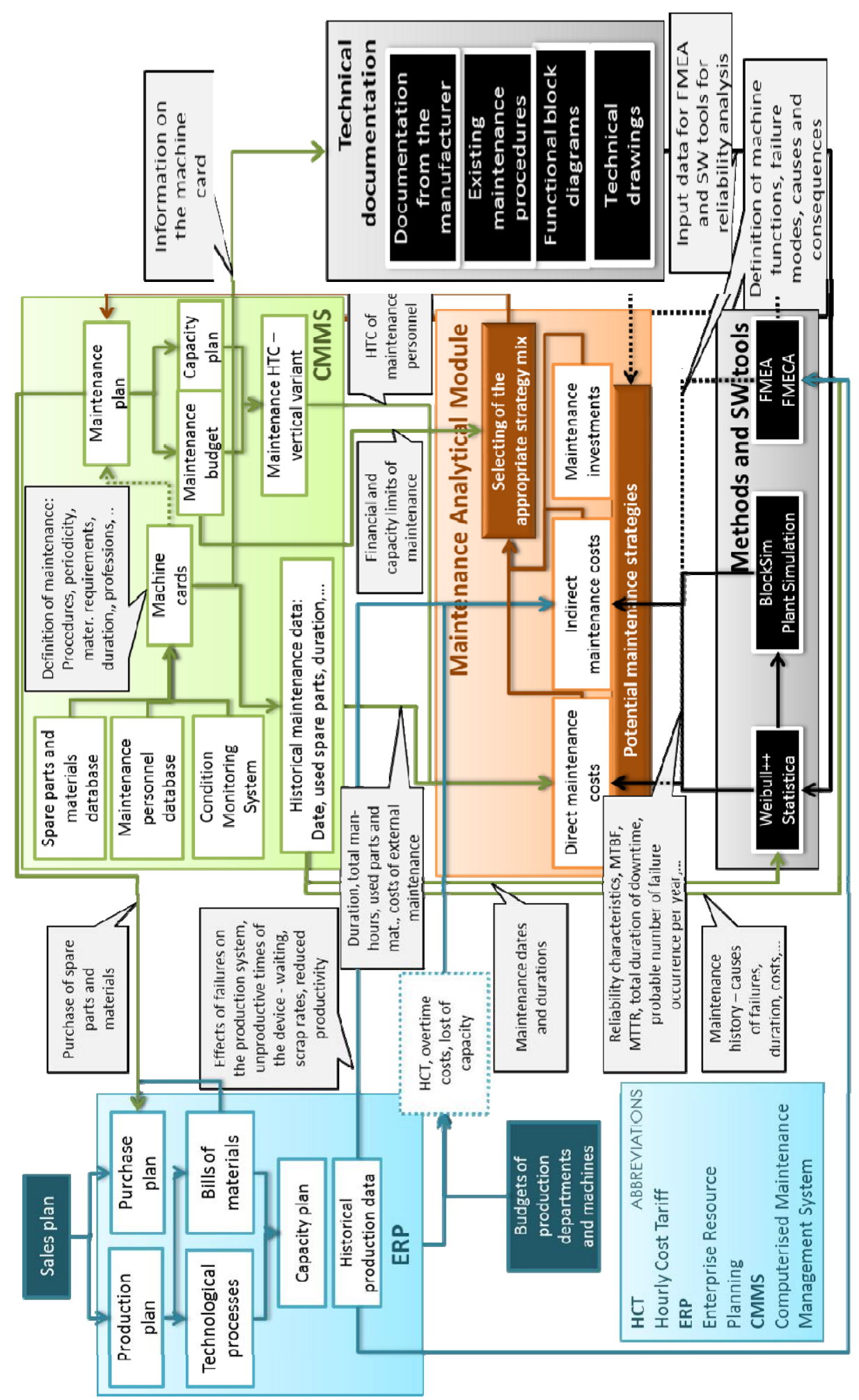

Figure 2 Information flows between information systems used within the methodology [7] 
- provides sensitivity analysis and simulations of the impact of changes in various inputs on the overall costs of maintenance, production capacity and other characteristics (e.g. in case of lack of empirical data);

- provides financial arguments to maintenance managers for negotiations with top management on investments in the maintenance system development.

Model MAM represents prototype of the information system programmed in MS Excel, which is used for presentation of basic structure, verification of the model functionality and illustration of the links between individual model parts. For demonstration of the model functionality the case study for system of ten machines was defined.

The model structure is hierarchical and is shown on the fig. 3 .

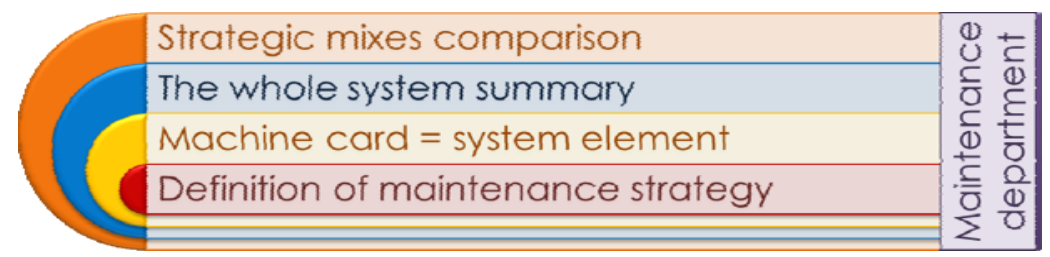

Figure 3 Model MAM structure [7]

The basic level, which forms the core of the model, represent the sheets definition of maintenance strategy, where for each element of the system (machine/equipment) the parameters of individual maintenance strategy are assigned (e.g. preventive maintenance periodicity, length of maintenance procedure, average length of downtime due to failure, direct maintenance costs, etc.).

The second level represent machine cards that aggregates all the information from the sheets definition of maintenance strategy and add additional data needed especially for indirect maintenance costs quantification (e.g. machine purchasing price, cost of space, insurance, personnel cost of the machine operator, cost of lost capacity, capacity structure, etc.).

Third level represent the whole system summary, which aggregates information from all machine cards about individual system elements in unified structure.

This sheet provides wide range of output characteristics, which can be used by maintenance managers for selecting of maintenance strategy mix suitable for individual system element (machine). Selected output characteristics provided by the MAM model are shown in the table 1.

Table 1 Output characteristics for different maintenance strategies provided by the MAM model

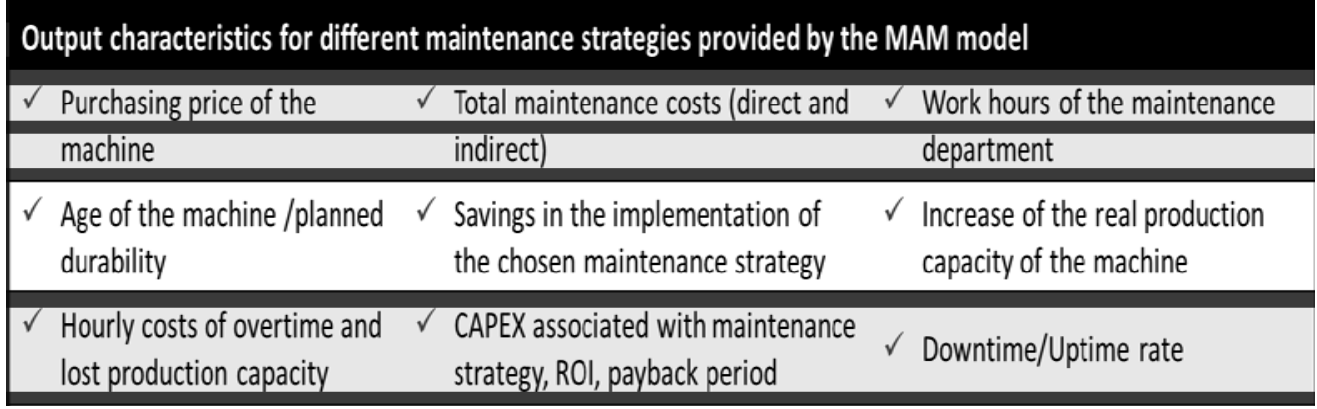


The highest level represents overall comparison of various maintenance strategy mixes.

\begin{tabular}{|c|c|c|c|c|c|c|}
\hline \multirow{2}{*}{$\begin{array}{l}\text { (4). (2) } \\
\text { Strategy Mix Variant }\end{array}$} & \multicolumn{5}{|c|}{ comparison: Strategy mixes } & \multirow{2}{*}{ * Maintenance strategy characteristic } \\
\hline & $1 * *$ & 2 & E & 4 & $=$ & \\
\hline Machine No. & & of chosen ma & chine mainte & nance strate & & \\
\hline M1 & s1 & \$3 & \$2 & s2 & \$2 & Strategy $\mathrm{S} 1$ is based on \\
\hline M2 & s1 & \$3 & $\$ 3$ & $\$ 3$ & \$3 & $\begin{array}{l}\text { corrective maintenance. Only } \\
\text { basic preventive maintenance }\end{array}$ \\
\hline M3 & s1 & s1 & s1 & s1 & s1 & $\begin{array}{l}\text { basic preventive maintenance } \\
\text { procedures are implemented }\end{array}$ \\
\hline M4 & s1 & S2 & \$2 & \$2 & \$2 & procedures are implemented \\
\hline M5 & s1 & S3 & $\$ 3$ & S2 & \$2 & \\
\hline M6 & s1 & s1 & s1 & s1 & \$1 & \\
\hline M7 & s1 & \$3 & $\$ 3$ & \$3 & \$2 & Strategy $\mathbf{S 2}$ is characterised by \\
\hline M8 & s1 & s3 & \$3 & s3 & \$2 & $\begin{array}{l}\text { Strategy S2 is characterised by } \\
\text { high proportion of preventive }\end{array}$ \\
\hline M9 & s1 & \$3 & \$3 & s1 & $\$ 3$ & $\begin{array}{l}\text { maintenance. } \\
\text { maint proportion of preventive }\end{array}$ \\
\hline M10 & s1 & s1 & s1 & s1 & s1 & \\
\hline Total mainteanance costs $\quad[\mathrm{CZK}]$ & 4383993 & 3517044 & 3521086 & 3669485 & 3769269 & \\
\hline Direct maintenance costs $\quad[\mathrm{CZK}]$ & 2332250 & 2456788 & 2405071 & 2433491 & 2446609 & \\
\hline Indirect maintenance costs $\quad$ [CZK] & 2051742 & 1060256 & 1116015 & 1235994 & 1322660 & Strategy S3 - condition based \\
\hline Expected savings & a & 1080868 & 1020692 & 789392 & 652660 & $\begin{array}{l}\text { maintenance is used for } \\
\text { elimintation of the risk of }\end{array}$ \\
\hline Investment needed & o & 1605000 & 1250000 & 760000 & 400000 & selected Failure Mode. \\
\hline Hours woked-maintenance [Hours] & 3401 & 2603 & 2781 & 3113 & 3217 & \\
\hline Downtime/Uptime & $3,89 \%$ & $2,04 \%$ & $2,28 \%$ & $2,43 \%$ & $2,71 \%$ & $\mathrm{PM}=\mathrm{CBM}$ \\
\hline
\end{tabular}

Figure 4 Overall comparison of five variants of maintenance strategy mixes [7]

This sheet enables maintenance managers to compare impacts of various strategy mixes implementation and to choose appropriate strategy mix, which brings the highest benefits for the whole system.

\section{CONCLUSION}

This article describes basic principles of the methodology for selecting appropriate maintenance strategy and developed software tool - MAM decision support model. These tools are beneficial mostly for maintenance managers, whom provides information and methodological support.

The MAM model was designed as a functional prototype of managerial information system for ten interdependent elements (machines No. 1 - No. 10) of one production process. This model was filled with model data about individual machines derived on the basis of experience gained during the processing of the master's degree thesis Implementation of the preventive maintenance system in Czech industrial company [8].

Designed prototype of the information system clearly shows potential benefits of implementation of above-mentioned methodology and use of the MAM model. The biggest obstacle of application in companies is insufficient data about maintenance. The survey among Czech companies shows that only $25 \%$ of respondents have implemented some kind of Computerized Maintenance Management System (CMMS), which is an essential element for application of the methodology. The wider use of these modern software tools can be seen as a potential way for significant improvement of maintenance management level not only in Czech enterprises.

\section{REFERENCES}

[1] ALSYOUF, I. The role of maintenance in improving companies' productivity and profitability. Int. J. Production Economics [online]. 2006, c. 105, s. 70-78 [cit. 2012-07-02]. Accessible from: www.sciencedirect.com

[2] MOORE, Ron. Selecting the right manufacturing improvement tools: What tool? When? Burlington: Butterworth-Heinemann, 2007, xxii, 390 s. ISBN 07-5067916-6. 
[3] Pinjala, s. K., 1. Pintelon A A. Vereecke. An empirical investigation on the relationship between business and maintenance strategies. International Journal of Production Economics [online]. 2006, roč. 104, č. 1, s. 214-229 [cit. 2012-0924]. ISSN 09255273. DOI: 10.1016/j.ijpe.2004.12.024. Accessible from: http://linkinghub.elsevier.com/retrieve/pii/S09255273050 00216

[4] Rausand, Marvin. Reliability centered maintenance. Reliability engineering [online]. 1998, 60/2, s. 121-132 [cit. 2012-08-03]. ISSN 09518320. DOI: 10.1016/S0951-8320(98)83005-6. Available from: http://linkinghub. elsevier.com/retrieve/pii/S0951832098830056

[5] Zhou, X., L. XI a J. LEE. Reliability-centered predictive maintenance scheduling for a continuously monitored system subject to degradation. Reliability engineering [online]. 2007, 92/4, s. 530-534 [cit. 2012-10-07]. ISSN 09518320. DOI: 10.1016/j.ress.2006.01.006. Available from: http://linkinghub.elsevier.com /retrieve/pii/S0951832006000305

[6] Zilka, M. Survey of the maintenance management level in industrial enterprises in Czech Republic. In: Maintenance 2012. Zenica: University of Zenica, 2012, 1, p. 136-142. ISSN 1986-583X.

[7] Zilka, M. Strategy of maintenance system in industrial enterprise. Prague, 2013. Doctoral thesis. Czech Technical University in Prague.

[8] Kadam Nivedita Arun M.T. Telsang, Production Planning Module of ERP For Small Scale Industry, International Journal of Production Technology and Management, 3(1), 2012, pp. 01-08.

[9] Kesavulu.A, Mr. F.Anandraju and Dr. M.L.S.Deva Kumar, Production of Composite Material, International Journal of Mechanical Engineering and Technology, 5(9), 2014, pp. 394-399.

[10] Zilka, M. Implementation of the preventive maintenance system in Czech industrial company. Prague, 2006. Master's degree thesis. Czech Technical University in Prague. 